
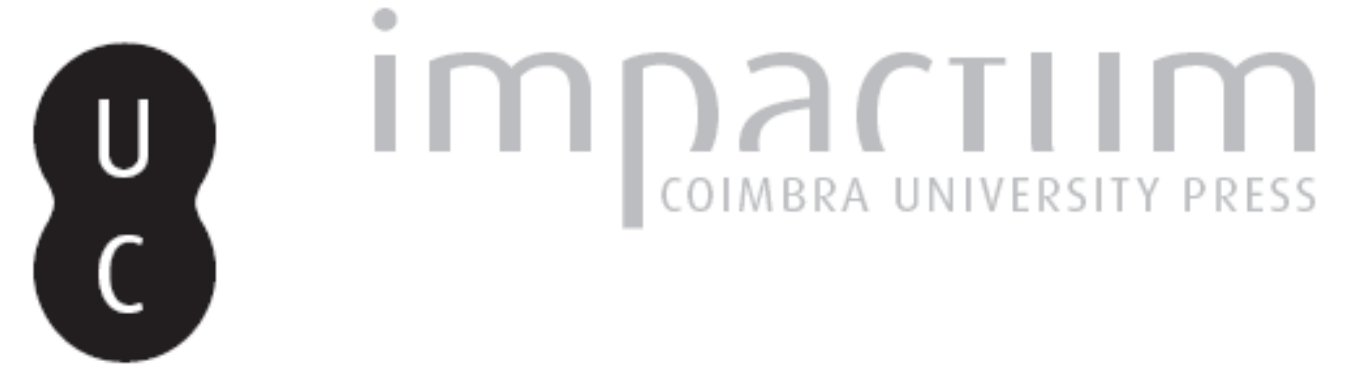

\title{
[Recensão a] Patrick Le Roux, L'Armée Romaine et l'Organisation des Provinces İbériques d'Auguste à l'Invasion de 409
}
Autor(es):
D’Encarnação, José

Publicado por: Imprensa da Universidade de Coimbra

URL persistente:

URI:http://hdl.handle.net/10316.2/45668

DOI:

DOI:https://dx.doi.org/10.14195/1647-8657_24_16

Accessed : $\quad$ 26-Apr-2023 12:28:48

A navegação consulta e descarregamento dos títulos inseridos nas Bibliotecas Digitais UC Digitalis, UC Pombalina e UC Impactum, pressupõem a aceitação plena e sem reservas dos Termos e Condições de Uso destas Bibliotecas Digitais, disponíveis em https://digitalis.uc.pt/pt-pt/termos.

Conforme exposto nos referidos Termos e Condições de Uso, o descarregamento de títulos de acesso restrito requer uma licença válida de autorização devendo o utilizador aceder ao(s) documento(s) a partir de um endereço de IP da instituição detentora da supramencionada licença.

Ao utilizador é apenas permitido o descarregamento para uso pessoal, pelo que o emprego do(s) título(s) descarregado(s) para outro fim, designadamente comercial, carece de autorização do respetivo autor ou editor da obra.

Na medida em que todas as obras da UC Digitalis se encontram protegidas pelo Código do Direito de Autor e Direitos Conexos e demais legislação aplicável, toda a cópia, parcial ou total, deste documento, nos casos em que é legalmente admitida, deverá conter ou fazer-se acompanhar por este aviso.

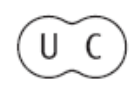


FACULDADE DE LETRAS

INSTITUTO DE ARQUEOLOGIA

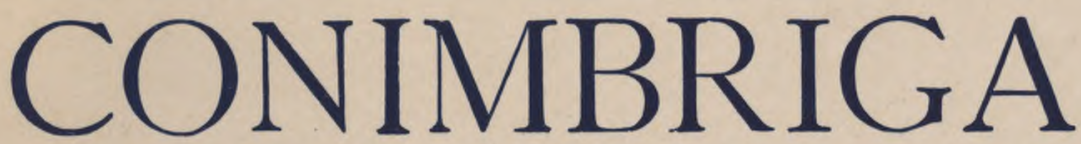

VOLUMEXXIV

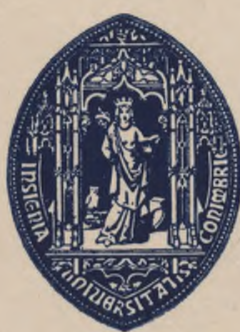

UNIVERSIDADE DE COIMBRA

1985 
utilização do registo vídeo e das técnicas audiovisuais, o projecto de uma ficha informatizada.

O segundo tema englobou os casos concretos: origem, situação e projecto de museus europeus - franceses, alemães, húngaros, jugoslavos e, sobretudo, italianos. Testemunhos eloquentes das mais variadas experiências - de exposição (temática? cronológica?...), de restauro e de conservação (uso do gesso, problemas de líquenes...) - $\mathrm{cm}$ locais diversos e com material epigráfico diferente, acompanhados de esclarecedoras ilustrações, onde facilmente se poderão colher sugestões importantes.

Quase todos os museus portugueses - nacionais e regionais - contam no seu recheio monumentos epigráficos. Os catálogos até agora publicados são díspares na qualidade e no conteúdo; os ficheiros, praticamente inexistentes ou desprovidos de uma informação capaz. Que os nossos museólogos, à luz dos ensinamentos deste oportuno colóquio, contribuam - com os epigrafistas - para a valorização do património que lhes é confiado. Existem peças cuja beleza ou cujo valor histórico é susceptivel de transmitir ao grande público uma mensagem persistente - há que expô-las. Outras, porém, só aos especialistas interessam: integrarão as reservas, aí se possibilitando, muito embora, um contacto directo, fácil e agradável com o monumento em todos os seus pormenores. Os pequenos fragmentos, por seu turno, ficarão arrumados em prateleiras.

Pela sua especificidade, pelo hermetismo da sua mensagem e do seu significado, o monumento epigráfico arrisca-se, de facto, a ser, mais do que os os outros, no museu, uma peça morta. Competirá ao museólogo e ao epigrafista - enriquecidos ambos desde já com as brilhantes lições que este precioso volume encerra - fazê-lo airosamente ressuscitar na sua luzidia roupagem de importante objecto cultural.

JOSÉ D'ENCARNAÇ̃̃o

Patrick Le Roux, VArmée Romaine et VOrganisation des Provinces Ibériques d'Auguste à VInvasion de 409. Publications du Centre Pierre Paris, n. ${ }^{\circ}$ 8. Collection de la Maison des Pays Ibériques, n. ${ }^{\circ}$ 9. Diffusion De Boccard, Paris, 1982. 493 p.-j-5 fig.-|-16 estampas. [ISBN 2-7018$-0002-1$.

Não é, exactamente, a historia militar do exército hispanus, nem sequer o pretexto para nos embrenharmos na historia da romanização da Península: a obra analisa, de modo original, o conteúdo político-administrativo dum exército provincial i omano que constitui, em muitos aspectos, um cadinho de experiências, reflexo e actor das transformações suas contemporâneas. Fautor primordial da «hispanização» da Península Ibérica, como lhe chama Patrick Le Roux - ou, por outras palavras, da consciencialização da Hispânia como um todo, nacional mas sem veleidades autonómicas -, o exército hispânico é minuciosamente observado como elemento funcional de uma 
orientação política que provém das contradições e das condições dum poder central mas que se tempera no contacto íntimo com os condicionalismos próprios duma região sem guerra e sem soldados que na guerra se tornem gloriosos.

Não vamos, pois, encontrar no livro de Le Roux o esmiuçar longo e complexo das campanhas e marchas militares, das batalhas e seu rol de mortos; também não teremos aí o pólo oposto, no acentuar exclusivo duma «dinamização cultural» aqui deveras controversa. A temática situa-se exactamente no meio-termo, como, aliás, o próprio título deixa antever: história militar, sim, sem dúvida, mas interpretada à luz duma política administrativa que, de facto, unicamente a pode explicar. E o nosso voto é, desde já, que outros «exércitos provinciais» recebam, à luz desta pesquisa exemplar, um tratamento igual para que, duma vez por todas, se deixem de parte as generalidades e se tracem, com segurança, as linhas de uma investigação criadora haurida no caldear de todas as fontes disponíveis: literárias, arqueológicas, numismáticas e, sobretudo, epigráficas.

Se um defeito se pode apontar ao trabalho de P. Le Roux é o da sua vastidão e pormenor - a exigir, compactamente, uma concentração total do seu leitor. Porque VArmée Romaine... não é, apenas, a história da ocupação romana peninsular, vista do prisma do seu exército, que de seguida se lê; é, fundamentalmente, a análise pormenorizada e perspicaz de todos os dados, designadamente os epigráficos e literários, num constante dialogar com os estudos já feitos, as interpretações apontadas, as desatenções cometidas. Nada é aceite a priori — daí o acumular das notas e das explicações. Também não há um ponto de partida ao qual a argumentação cegamente se submeta: a sua ideia de que o exército romano da Hispânia foi um elemento activo das forças provinciais, «criador de uma estrutura cuja dinâmica se reflectia tanto na organização romana como na sociedade provincial» (p. 408), impõe-se pouco a pouco ao longo da obra, é o corolário lógico de exaustiva documentação compulsada.

Como escreve R. Étienne, no prefácio, o livro marca o começo de uma «nova história militar das províncias romanas». A prosseguir.

Depois de uma primeira introdução, em que aponta os dados da questão e as fontes para a sua abordagem, P. Le Roux estuda, no livro I, o nascimento do exército permanente, atribuindo nesse sentido às tropas acantonadas na Península - desprovidas, verdadeiramente, de um objectivo bélico preciso depois de completada a conquista - um papel experimental do maior interesse (cap. II) que levaria Vespasiano a fazer de Hispânia uma «província estratégica» (p. 157-160), que englobava a Bretanha, as Germânias, as Gálias e as Mauritânias; assim se evitava o isolamento dos exércitos e «se introduzia um novo equilíbrio de forças, susceptível de limitar as revoltas» (p. 161) como as que a crise de 68-69 vira surgir. Aliás, é de realçar a interpretação dada por Le Roux ao «segredo do Império» referido por Tácito (Hist. I, 4,2) a propósito da proclamação de Galba: tal segredo desvendado nada mais era do que a necessidade de criar um elo de transição entre o exército de cidadãos (da República) e o exército profissional (que se perfilava 
no horizonte); e esse elo era o exército provincial, que reunia em si as características de um e de outro (p. 140).

Constitui o livro II um olhar fundo para o interior deste exercitus hispanus, na sua roupagem pioneira de «exército da paz». Primeiro, os soldados: o catálogo epigráfico de 272 números, alinhado cronologicamente e comentado; as características e condições do serviço, o recrutamento (p. 171-290). Depois (p. 291-318), os centuriões e oficiais - ilustrados através de quadros sinópticos cuja paginação nem sempre foi fácil (p. 292 a 295, por exemplo). Finalmente (p. 319-356), um terceiro capítulo, que tem muito de original (devido sobretudo à utilização da onomástica), em que, através de cuidada leitura dos dados epigráficos, se procuram detectar os elementos susceptíveis de integrar o soldado na sociedade civil donde procede e onde, como veterano, novamente se vai inserir. E a análise contribui para esbater consideravelmente a ideia, que se julgava assente, de que o veterano constituiu forte elemento romanizador (os dados não o sugerem), assim como se confirma a tese de F. Vittinghoff, segundo a qual o nascimento de um município junto a um acampamento se prende, geralmente, menos com o desenvolvimento dos canabae do que com a presença próxima dum vicus indígena (p. 347).

Abarcando o período que vai desde 250 à invasão dos Vândalos, no Outono de 409, o livro III aborda, entre outros pontos, a questão da divisão administrativa empreendida por Garacala e por Diocleciano, a polémica acerca do (inexistente) limes hispanicus, para concluir sobre a imobilidade, o isolamento de um exército que, a largos passos, caminha para a «fossilização» (p. 400), porque já desprovido de conteúdo militar, porque os seus legionários se encontram «prisioneiros da rotina e das ordens» (p. 401).

História para ler e meditar, esta Varmèe romaine... de Patrick Le Roux é, também, um importante volume a consultar assiduamente, tão vasta e tão variada é a problemática que aborda. Daí que tenha pleno cabimento uma palavra de aplauso não somente para a extensa bibliografia citada como também, e sobretudo, para os completos e bem elaborados índices que a complementam (p. 437-485): de fontes, onomástico (nomes individuais, gentilicios, cognomes, divindades, imperadores e imperatores), geográfico e etnográfico, de assuntos. Mapas, plantas e fotografias ilustram, por fim, uma obra ímpar e a todos os títulos meritória.

Terminou P. Le Roux em 1979 a investigação que daria corpo a este trabalho. E se, de facto, ainda pôde incluir alguns dados surgidos depois, susceptíveis de enriquecerem o já bem nutrido catálogo, outros, porém, já não puderam entrar ou passaram despercebidos: estamos a recordar, por exemplo, a referência a Cornelius Bocchus, tribuno da III Legião Augusta (CIL II 5184), um veterano da XXII Legião Primigénia Pia Fiel (ILER 6387), o legado da mesma legião L. Marius Vegetinus Marcianus Minicianus Myrtilianus (CIL VI 1455 e 1456) que J.-N. Bonneville (MCV XVIII 1982 p. 19) dá como originário de Mértola. No entanto, por muitos outros testemunhos que ainda surjam, eles não vão decerto alterar o vigoroso quadro gizado.

José D'ENCARNAÇ̃̃o 